\title{
BMJ Global Health Equity in access to non-communicable disease medicines: a cross-sectional study in Kenya
}

\author{
Peter C Rockers, ${ }^{1}$ Richard O Laing, ${ }^{1,2}$ Veronika J Wirtz ${ }^{1}$
}

To cite: Rockers PC, Laing R0, Wirtz VJ. Equity in access to non-communicable disease medicines: a cross-sectional study in Kenya. BMJ Glob Health 2018;3:e000828. doi:10.1136/ bmjgh-2018-000828

\section{Handling editor Soumitra Bhuyan}

- Additional material is published online only. To view please visit the journal online (http://dx.doi.org/10.1136/ bmjgh-2018-000828).

Received 13 March 2018 Revised 24 May 2018 Accepted 26 May 2018
Check for updates

${ }^{1}$ Department of Global Health, Boston University School of Public Health, Boston, Massachusetts, USA ${ }^{2}$ Department of Demography and Population Studies, University of the Witwatersrand, Johannesburg, South Africa

Correspondence to Dr Peter C Rockers; prockers@bu.edu

\section{ABSTRACT}

Introduction Wealth-based inequity in access to medicines is an impediment to achieving universal health coverage in many low-income and middle-income countries. We explored the relationship between household wealth and access to medicines for non-communicable diseases (NCDs) in Kenya.

Methods We administered a cross-sectional survey to a sample of patients prescribed medicines for hypertension, diabetes or asthma. Data were collected on medicines available in the home, including the location and cost of purchase. Household asset information was used to construct an indicator of wealth. We analysed the relationship between household wealth and various aspects of access, including the probability of having NCD medicines at home and price paid.

Results Among 639 patients interviewed, hypertension was the most prevalent NCD $(69.6 \%)$, followed by diabetes $(22.2 \%)$ and asthma $(20.2 \%)$. There was a positive and statistically significant association between wealth and having medicines for patients with hypertension $(p=0.020)$ and asthma $(p=0.016)$, but not for diabetes $(p=0.160)$. Poorer patients lived farther from their nearest health facility $(p=0.050)$. There was no relationship between household wealth and the probability that the nearest public or non-profit health facility had key NCD medicines in stock, though less poor patients were significantly more likely to purchase medicines at better stocked private outlets. The relationship between wealth and median price paid for metformin by patients with diabetes was strongly u-shaped, with the middle quintile paying the lowest prices and the poorest and least poor paying higher prices. Patients with asthma in the poorest wealth quintile paid more for salbutamol than those in all other quintiles. Conclusion The poorest in Kenya appear to face increased barriers to accessing NCD medicines as compared with the less poor. To achieve universal health coverage, the country will need to consider pro-poor policies for improving equity in access.

\section{INTRODUCTION}

Equitable access to essential medicines is a key component of universal health coverage and health as a human right. ${ }^{2}$ A WHO report published in 2011 states, "inequity and discrimination in access to essential medicines remain the key public health

\section{Key questions}

\section{What is already known?}

- Equitable access to essential medicines is a key component of universal health coverage.

- Recent research has identified a wealth gradient in access to medicines for non-communicable diseases in low-income and middle-income countries.

\section{What are the new findings?}

- We find that the poorest patients in Kenya are least likely to have medicines to treat hypertension, diabetes and asthma.

- We present important new evidence that the poorest pay higher prices for their medicines, creating an undue financial burden on the most vulnerable households.

\section{What do the new findings imply?}

- To achieve universal health coverage, Kenya will need to consider policies for improving equity in access to medicines.

challenge of our times". ${ }^{3}$ Recent studies have documented inequity in access to medicines between and within countries, regardless of income level, along several important dimensions including gender, ethnicity, geography and wealth. ${ }^{4-9}$ Access has been found to be lower for women as compared with men and for ethnic minorities. ${ }^{4-7}$ Medicine availability is consistently found to be lower in rural areas as compared with urban areas. 89

Wealth is one of the best studied dimensions of inequity in access to medicines. Recent evidence suggests that there is a strong wealth gradient in access to medicines for non-communicable diseases (NCDs) in many low-income and middle-income countries. ${ }^{10} 11$ This may be driven in part by price and affordability barriers, which disproportionately affect poor households. ${ }^{12}$ With many countries moving towards more extensive service coverage, medicine availability has recently improved in some places, but even then wealth inequities may remain due to differential access to 
health insurance coverage. ${ }^{13}$ Availability barriers may also be important; the poor often reside in areas more distant from outlets with a reliable stock of essential medicines. Finally, the poor may face discrimination at public and private sector medicine outlets that serve as a barrier to access. ${ }^{14}$ If left unaddressed, these barriers will impede progress towards achieving universal health coverage and Sustainable Development Goal Target 3.8. ${ }^{15}$

In this paper, we explore the relationship between an asset-based indicator of wealth and access to medicines in a sample of households in Kenya with at least one member diagnosed and prescribed treatment for at least one of hypertension, diabetes or asthma. First, we describe the relationship between household wealth and the primary outcome of interest: having medicines to treat their NCD in the home. Then, to better understand this relationship, we investigate wealth gradients in dimensions of medicine availability, including geographical proximity to nearby health facilities and medicine stocks at those facilities. Next, we describe how prices paid for common NCD medicines vary by household wealth. We conclude with a discussion of our findings and reflections on the importance of wealth dimensions of equity in access to essential medicines.

\section{METHODS}

\section{Study design and setting}

The study was conducted in eight counties in Kenya. In September 2016, a cross-sectional survey was administered to households during a baseline visit for a cluster-randomised controlled trial testing an access-to-medicines intervention (ClinicalTrials.gov registration number NCT02773095). ${ }^{16}$

In Kenya, nearly half of the population lives below the national poverty line ${ }^{17}$ Per capita expenditure on health is around US $\$ 70,33 \%$ of which is out-of-pocket. ${ }^{18}$ The prevalence of hypertension in the country is $22 \%$ and the prevalence of diabetes is $5 \% \cdot{ }^{19}$ Recent studies have estimated the prevalence of asthma in Kenyan schoolchildren between $18 \%$ and $21 \% .{ }^{20}{ }^{21}$ Overall, NCDs account for $27 \%$ of deaths ( 370000 per year) among people between 30 and 70 years old. ${ }^{22}$

Patients in Kenya primarily access medicines at public, not-for-profit or private for-profit outlets. Private sector medicine purchases are almost entirely out-of-pocket; in the public and not-for-profit sector-Ministry of Health facilities or facilities affiliated with faith-based organisations-decisions on price are made at the district and facility level, while some facilities offer NCD medicines free of charge; at other facilities, patients are charged either the full price or a partial cost-recovery fee. ${ }^{23}$ According to a recent household survey, $82 \%$ of patients in Kenya pay out-of-pocket for their NCD medicines. ${ }^{10}$

\section{Participants}

A sample of households was randomly selected from eight study counties using a two-stage cluster design. In the first stage, 10 villages were selected from within each county with probability proportional to population size based on data collected during the most recent census. In the second stage, 10 eligible households in each village were randomly selected and recruited into the study. The overall target sample for the study was 800 participants, based on the power calculation conducted prior to the start of the intervention trial. ${ }^{16}$ To identify eligible households, 10 random sets of GPS coordinates were selected within each village and study enumerators visited households in order of nearness to each set of coordinates until an eligible household was found. To be eligible for the study, at least one household member age 18 years or older had to have been diagnosed and prescribed treatment for one of four NCD conditions: cardiovascular disease (including hypertension, heart failure and dyslipidaemia), diabetes, asthma or breast cancer. All members of selected households who fit the eligibility criteria were invited to participate in the study.

\section{Data collection}

Study data were collected from two sources: households and health facilities. Household data included demographics, indicators of wealth, monthly expenditures on medicine and healthcare, and location and price of recent medicine purchases. All prices were collected in Kenyan Shillings and converted to US dollars for analysis. All public and non-profit health facilities in the eight study counties were visited and information on medicine stock levels were collected along with GPS coordinates. In Kenya, most non-profit health facilities are operated by faith-based organisations. For-profit facilities and drug outlets were not included in the analysis because they were not the focus of the intervention trial. ${ }^{16} \mathrm{~A}$ team of assessors attended a 2-week training course prior to the start of data collection.

\section{Variables}

The primary outcome of interest is the probability of having at least one NCD medicine at the home. Study participants were asked during the initial unannounced enumeration visit whether they had medicines in their home for treatment of their $\operatorname{NCD}(\mathrm{s})$, and those who indicated that they did were asked to bring them to the interviewer to view for confirmation. For each confirmed medicine, interviewers recorded information on the name, pack size and dosage. Respondents were then asked about where they purchased each medicine they presented and the price they paid. Medicine names were checked by the study team and confirmed to be NCD treatments during the analysis. Medicine prices were converted to price per monthly dose for analysis.

A continuous indicator of household wealth was constructed using principal component analysis of household asset information. ${ }^{24}$ Household assets were assessed during the survey visit using a list of potential assets consistent with the 2014 Kenya Demographic and Health 
Survey. ${ }^{25}$ The study population was split into equally sized wealth quintiles for the analysis.

\section{Analysis}

First, we describe the study population. Then, we graph the relationship between household wealth and the probability of having an NCD medicine at the home for respondents with hypertension, diabetes and asthma. Next, we describe the relationship between household wealth and various dimensions of medicine availability, including distance to nearby public and non-profit facilities, the stock of medicines at those facilities and the probability that patients purchased their medicines in the private sector. Finally, we present two graphs describing the relationship between household wealth quintile and prices paid for common NCD medicines, including hydrochlorothiazide (HCTZ) for hypertension, metformin for diabetes and salbutamol inhaler for asthma. The first graph describes the proportion of patients with medicines who received them free of charge. The second graph presents median prices paid for medicines among those who paid something. SEs were clustered within villages to account for the two-stage sampling procedure. Analyses were conducted using Stata statistical software. ${ }^{26}$

\section{RESULTS}

\section{Study population}

Overall, 639 individuals in 86 villages were enrolled in the study (table 1). There was a total of 593 households included in the study; 46 households had two participants. The sample target of 800 participants was not reached because the reported prevalence of NCDs in three of the study counties was lower than expected. More than two-thirds of participants were women, and around half were age 61 years or older. One quarter of participants had completed primary school, and less than half of households had electricity. The full list of household assets included in the wealth indicator are summarised in the online supplementary file. Hypertension was the most prevalent NCD reported $(69.6 \%)$, followed by diabetes $(22.2 \%)$ and asthma $(20.2 \%)$. No patients with breast cancer were identified during recruitment.

\section{Medicines in the home}

Among respondents with hypertension, $73.2 \%$ were confirmed to have a medicine for their disease in their home. The same was true for $73.9 \%$ of respondents with diabetes and $53.5 \%$ of respondents with asthma. Among respondents in the poorest wealth quintile

Table 1 Description of the study population

\begin{tabular}{|c|c|c|c|c|c|c|}
\hline & $\begin{array}{l}\text { Full sample } \\
(n=639)\end{array}$ & $\begin{array}{l}\text { Q1 } \\
\text { (poorest) } \\
\text { (n=126) }\end{array}$ & $\begin{array}{l}Q 2 \\
(n=129)\end{array}$ & $\begin{array}{l}Q 3 \\
(n=129)\end{array}$ & $\begin{array}{l}Q 4 \\
(n=128)\end{array}$ & $\begin{array}{l}\text { Q5 } \\
\text { (least poor) } \\
(n=127)\end{array}$ \\
\hline & $n(\%)$ & n (\%) & n (\%) & n (\%) & n (\%) & n (\%) \\
\hline \multicolumn{7}{|l|}{ Demographics } \\
\hline Women & $443(69.3)$ & 89 (70.6) & $93(72.1)$ & 92 (71.3) & $79(61.7)$ & $87(68.5)$ \\
\hline \multicolumn{7}{|l|}{ Age } \\
\hline$<40$ & $92(14.4)$ & $33(26.2)$ & $22(17.1)$ & $12(9.3)$ & $19(14.8)$ & $6(4.7)$ \\
\hline $40-60$ & $243(38.0)$ & $30(23.8)$ & $56(43.4)$ & $46(35.7)$ & $52(40.6)$ & $59(46.5)$ \\
\hline $61+$ & $304(47.6)$ & $63(50.0)$ & $51(39.5)$ & $71(55.0)$ & $57(44.5)$ & $62(48.8)$ \\
\hline Completed primary school & $165(25.8)$ & $6(4.8)$ & $21(16.3)$ & $29(22.5)$ & $46(35.9)$ & $63(49.6)$ \\
\hline Household members, mean (SD) & $5.2(3.5)$ & $5.4(3.3)$ & $6.2(4.8)$ & $4.6(2.8)$ & $5.3(3.1)$ & $4.5(2.7)$ \\
\hline \multicolumn{7}{|l|}{ Household assets } \\
\hline Electricity & $270(42.3)$ & $3(2.4)$ & 17 (13.2) & $41(31.8)$ & $95(74.2)$ & $114(89.8)$ \\
\hline Mobile phone & $585(91.6)$ & $87(69.1)$ & $118(91.5)$ & $127(98.5)$ & $126(98.4)$ & $127(100.0)$ \\
\hline Bicycle & $186(29.1)$ & $10(7.9)$ & $53(41.1)$ & $35(27.1)$ & $34(26.6)$ & $54(42.5)$ \\
\hline Television & 227 (35.5) & $0(0.0)$ & $9(7.0)$ & $18(14.0)$ & 77 (60.2) & $123(96.9)$ \\
\hline \multicolumn{7}{|l|}{ Health } \\
\hline \multicolumn{7}{|l|}{ Non-communicable disease } \\
\hline Hypertension & $445(69.6)$ & $75(59.5)$ & $84(65.1)$ & $96(74.4)$ & $88(68.8)$ & $102(80.3)$ \\
\hline Diabetes & $142(22.2)$ & $17(13.5)$ & $28(21.7)$ & 27 (20.9) & $34(26.6)$ & $36(28.4)$ \\
\hline Heart failure & $24(3.8)$ & $6(4.8)$ & $2(1.6)$ & $3(2.3)$ & $7(5.5)$ & $6(4.7)$ \\
\hline Dyslipidaemia & $4(0.6)$ & $2(1.6)$ & $0(0.0)$ & $1(0.8)$ & $0(0.0)$ & $1(0.8)$ \\
\hline Asthma & $129(20.2)$ & $35(27.8)$ & $31(24.0)$ & $23(17.8)$ & $25(19.5)$ & $15(11.8)$ \\
\hline More than one disease & $100(15.6)$ & $9(7.1)$ & $16(12.4)$ & $19(14.7)$ & $26(20.3)$ & 30 (23.6) \\
\hline
\end{tabular}




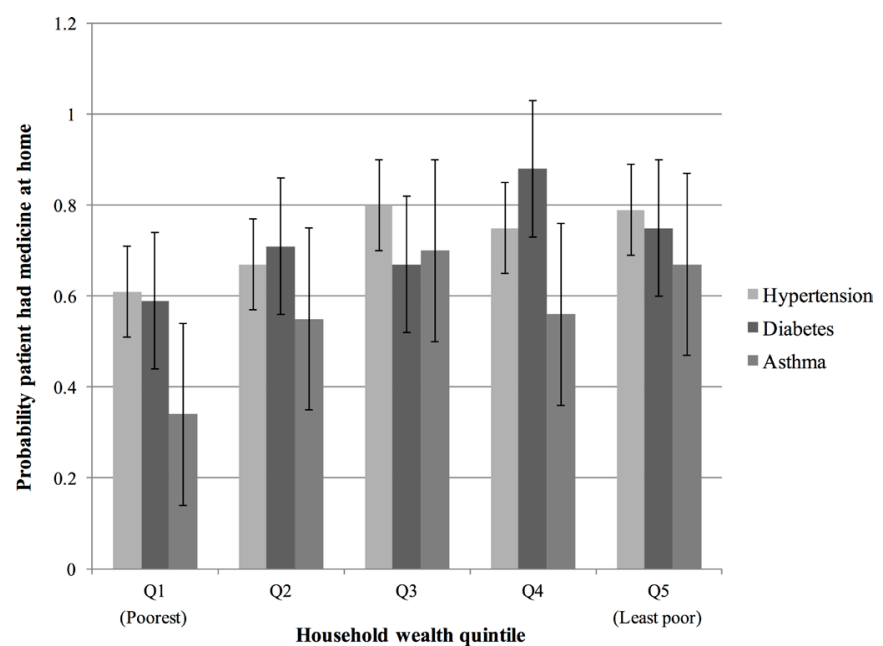

Figure 1 Probability that respondent had a medicine for their non-communicable disease in their home.Bars indicate 95\% Cls. All SEs adjusted to account for clustering within villages. Test for trend in relationship between wealth quintile and probability patient has medicine for hypertension: $\mathrm{p}=0.020$. Test for trend in relationship between wealth quintile and probability patient has medicine for diabetes: $p=0.160$. Test for trend in relationship between wealth quintile and probability patient has medicine for asthma: $p=0.016$.

with hypertension, diabetes and asthma, $61.3 \%, 58.8 \%$ and $34.3 \%$ had medicines, respectively, compared with $79.4 \%, 75.0 \%$ and $66.7 \%$ among those in the least poor wealth quintile (figure 1). There was a positive and statistically significant wealth gradient in the probability of having medicines among respondents with hypertension $(\mathrm{p}=0.020)$ and asthma $(\mathrm{p}=0.016)$. Among those with diabetes, there appears to be a similar positive gradient though the relationship is not statistically significant $(\mathrm{p}=0.160)$.

Households in the poorest wealth quintile reported spending US $\$ 7.65$ per month on medicines, while households in the least poor wealth quintile reported spending more than twice that amount (US\$15.93) (online supplementary file). There was a significant positive wealth gradient in monthly household expenditures on medicines $(\mathrm{p}<0.001)$ and on outpatient services overall $(p<0.001)$. Households in the poorest wealth quintile spent a larger proportion of their total monthly outpatient budget on medicines $(89.2 \%)$ as compared with households in the least poor wealth quintiles $(80.1 \%)$.

\section{Availability of medicines}

There was a significant negative relationship between wealth and distance to the nearest health facility $(\mathrm{p}=0.050$; table 2). Households in the poorest wealth quintile were on average $8.1 \mathrm{~km}$ from their nearest health facility while households in the least poor quintile were $5.2 \mathrm{~km}$ away. The poorest households were also more likely to be nearest to a public rather than non-profit facility. There was no relationship between household wealth and the probability that the nearest facility had key NCD medicines in stock. There was a significant positive relationship between wealth and the probability of purchasing medicines from private sector outlets for patients with hypertension $(\mathrm{p}=0.009)$, diabetes $(\mathrm{p}=0.042)$ and asthma $(\mathrm{p}=0.001)$.

Table 2 Availability of medicines

\begin{tabular}{|c|c|c|c|c|c|c|}
\hline & \multicolumn{5}{|c|}{ Wealth quintile } & \multirow[b]{2}{*}{$\mathbf{P}$ values } \\
\hline & $\begin{array}{l}\text { Q1 } \\
\text { (poorest) }\end{array}$ & Q2 & Q3 & Q4 & $\begin{array}{l}\text { Q5 } \\
\text { (least poor) }\end{array}$ & \\
\hline \multicolumn{7}{|l|}{ Distance to health facilities (km) } \\
\hline Nearest facility & $8.11(1.56)$ & $9.01(1.33)$ & $5.25(0.93)$ & $5.88(1.46)$ & $5.22(1.22)$ & 0.050 \\
\hline Nearest public facility & $10.98(1.48)$ & $12.89(1.67)$ & $9.69(1.27)$ & $10.52(2.05)$ & $9.44(1.36)$ & 0.285 \\
\hline Nearest non-profit facility & $13.56(2.20)$ & $12.59(1.88)$ & $6.95(0.87)$ & $7.92(1.27)$ & $6.70(1.09)$ & 0.002 \\
\hline $\begin{array}{l}\text { Probability nearest facility is } \\
\text { public }\end{array}$ & $0.54(0.08)$ & $0.37(0.08)$ & $0.30(0.07)$ & $0.30(0.07)$ & $0.29(0.07)$ & 0.020 \\
\hline \multicolumn{7}{|c|}{ Probability medicine available at nearest facility } \\
\hline HCTZ (hypertension) & $0.20(0.07)$ & $0.25(0.08)$ & $0.20(0.07)$ & $0.22(0.07)$ & $0.27(0.09)$ & 0.624 \\
\hline Metformin (diabetes) & $0.73(0.08)$ & $0.71(0.08)$ & $0.67(0.10)$ & $0.75(0.08)$ & $0.74(0.08)$ & 0.752 \\
\hline Salbutamol inhaler (asthma) & $0.38(0.08)$ & $0.37(0.09)$ & $0.57(0.09)$ & $0.43(0.09)$ & $0.55(0.09)$ & 0.109 \\
\hline \multicolumn{7}{|c|}{ Probability medicine purchased in private sector } \\
\hline Hypertension & $0.49(0.06)$ & $0.40(0.07)$ & $0.50(0.06)$ & $0.59(0.06)$ & $0.67(0.05)$ & 0.009 \\
\hline Diabetes & $0.41(0.12)$ & $0.32(0.09)$ & $0.48(0.10)$ & $0.50(0.09)$ & $0.61(0.09)$ & 0.042 \\
\hline Asthma & $0.36(0.07)$ & $0.45(0.09)$ & $0.65(0.11)$ & $0.72(0.09)$ & $0.67(0.11)$ & 0.001 \\
\hline
\end{tabular}

All data are mean values with SD provided in parentheses.

HCTZ, hydrochlorothiazide. 


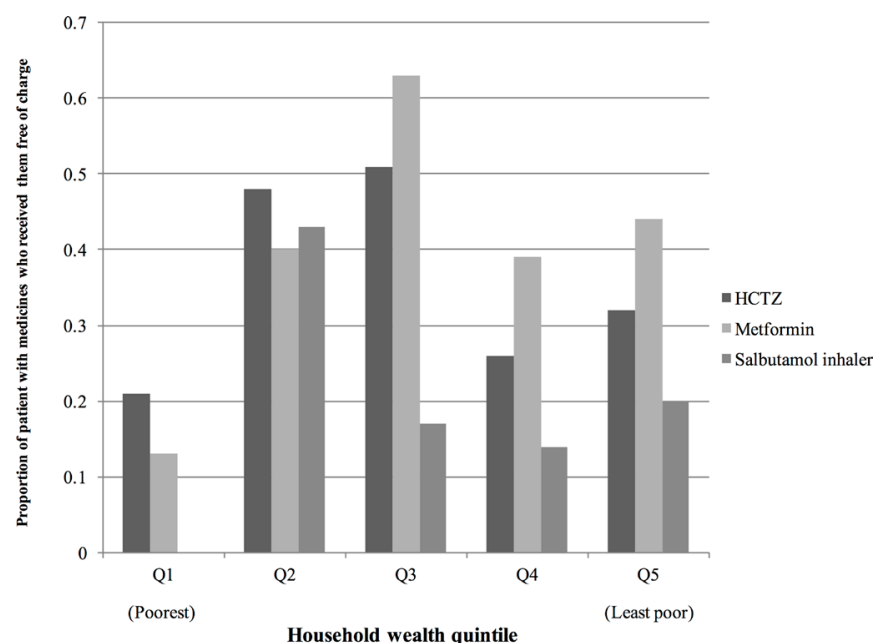

Figure 2 Proportion of respondents with medicines who received them free of charge. No patients in Q1 received salbutamol free of charge. HCTZ, hydrochlorothiazide.

\section{Affordability of medicines}

Among patients who had HCTZ $(25 \mathrm{mg})$, metformin (500 mg) or salbumatol inhaler $(100 \mu \mathrm{g})$ in their home, those in the poorest quintile were least likely to have received the medicine free of charge (figure 2). Of the three medicines, salbutamol was received free of charge the least. Among those who paid something for HCTZ, the median price paid for the two poorest and two least poor wealth quintiles was $\$ 0.75$ (figure 3 ); the median price paid in the middle quintile was slightly lower at $\$ 0.50$. The median price paid was high among the poorest quintile for metformin (US\$2.67 per monthly dose; figure 4) and salbutamol inhaler (US\$6.00 per inhaler; figure 5). For metformin, the relationship between wealth and median price paid is $\mathrm{u}$-shaped, with lower prices paid by those in the middle of the distribution and higher prices paid by the poorest and the least poor quintiles. For salbutamol, the poorest quintile paid more than all other quintiles. Additional detail on medicine price data

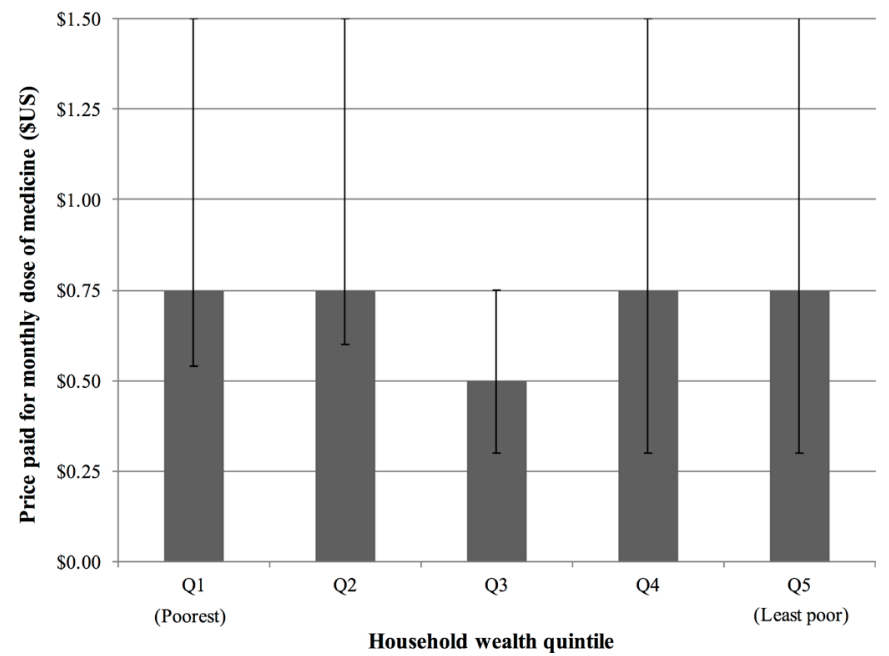

Figure 3 Median price paid per monthly dose for hydrochlorothiazide $(25 \mathrm{mg})$. Bars indicate interquartile range.

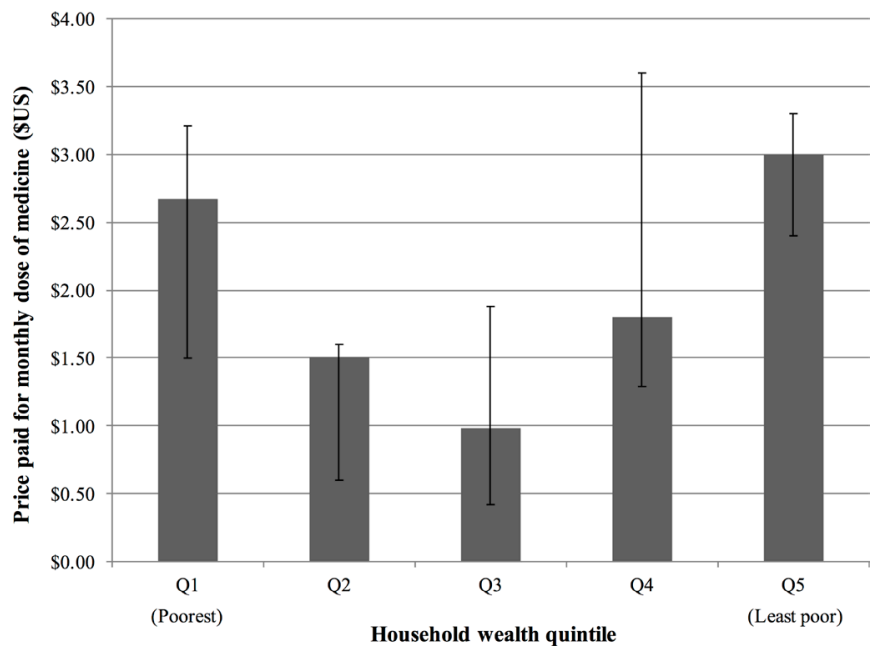

Figure 4 Median price paid per monthly dose for metformin (500 mg). Bars indicate interquartile range.

is provided in the online supplementary file. Combining those who received their medicines for free with those who paid something, the poorest quintile paid the most for all medicines.

\section{DISCUSSION}

We investigated the relationship between household wealth and access to NCD medicines in Kenya. Our analysis generated three main findings. First, there is clear wealth gradient in access for patients with hypertension, diabetes and asthma; poorer households are less likely to have medicines for their NCD at home. Second, poorer households face greater availability barriers to access: they live farther from their nearest health facility and they are less likely to purchase from better stocked private drug sellers. Third, among patients who are able to purchase NCD medicines, the poorest consistently pay more. These findings have implications for future efforts to improve access in high-poverty settings like Kenya.

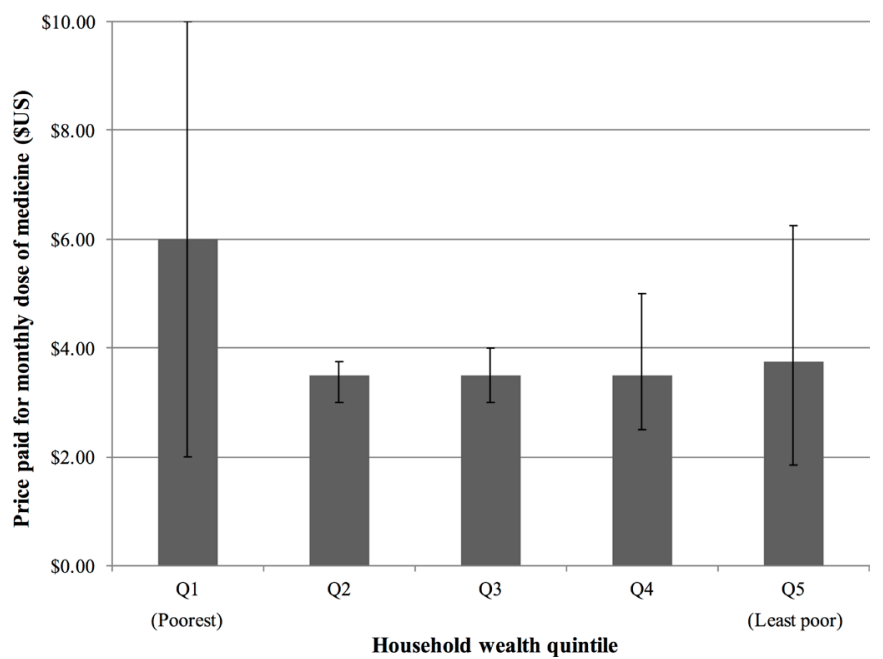

Figure 5 Median price paid per monthly dose for salbutamol inhaler $(100 \mu \mathrm{g})$. Bars indicate interquartile range. 
Many of the poorest patients with NCD in Kenya are not able to access medicines, while the majority of wealthier patients appear to have the medicines that they need. This finding suggests that key barriers to access are wealth related. Availability barriers that are geographical in nature are exacerbated by remoteness and poor access to transportation, which are both causes and consequences of poverty. ${ }^{27} 28$ Affordability barriers are exacerbated by resource constraints that the poorest households are more likely to face, as they have fewer resources to devote to medicines and to health overall. The poorest patients may also be unable to afford the cost of travelling to more distant private outlets where medicines are more likely to be in stock or more distant public or non-profit health facilities where medicines may be available at a lower price or free of charge. ${ }^{23}$

The poorest households in our study paid the most for their medicines. This was driven in part, but not entirely, by the poorest being least likely to access free medicines. While this finding may seem counterintuitive, previous research has identified a phenomenon referred to as the 'poverty penalty', which suggests a few plausible explanations. ${ }^{29}$ First, the poorest households are predominantly located in remote areas where competition within the market for medicines is weak, and as a result prices in these areas are often high. ${ }^{30}$ Within these communities, less poor households can often arrange for transportation to more distant outlets (eg, the nearest town) where prices are lower, but the poorest households may not have this option. This explanation is similar to the idea of 'food deserts'; indeed, 'medicine deserts' have been identified in the USA. ${ }^{32}$ Relatedly, the poorest may be less practised in 'shopping around' at multiple outlets to compare prices and find the most affordable option. ${ }^{33}$ Finally, poorer households may purchase medicines in smaller pack sizes at higher unit prices, potentially increasing gaps between purchases and the time without needed medicines. ${ }^{34}$ Future research should aim to understand why the poorest patients are least likely to access free medicines. Patients in the middle wealth quintile consistently paid the least for their medicines, which may reflect a greater ability to seek out the best price as compared with the poorest, and greater motivation to do so as compared with the least poor.

There were important limitations to this work. First, we did not collect data from individuals who may have needed NCD medicines but had not received an appropriate diagnosis or prescription. For this reason, our primary outcome should not be interpreted as a measure of unmet need for medicine, but rather a measure of access among patients assumed to be in the market for medicines. A previous study has measured access to NCD medicines in Kenya among a population that includes undiagnosed patients and found large gaps in access. ${ }^{10}$ Second, our data are cross-sectional and do not allow for strong causal inference. While we can describe the observed wealth gradient in access, we have limited ability to explain the causes for the gradient and suggest policy interventions. Third, we did not identify any patients with breast cancer during household recruitment and are not able to comment on medicine access among this important population.

\section{CONCLUSION}

The government of Kenya has committed to taking steps to achieve universal health coverage. ${ }^{35}$ Our findings suggest that among patients with NCD in the country, the poorest face increased barriers to accessing needed medicines. If the government is to be successful in achieving their ambitious goals, they will need to consider policies for improving equity in access to these medicines. NCD medicines are frequently out of stock at public facilities in Kenya and patients who are lucky enough to find them there must often pay for them out-of-pocket. Policies that ensure a reliable and affordable supply of medicines at public facilities may improve access to NCD medicines among the poorest patients in Kenya.

Acknowledgements Innovations for Poverty Action managed data collection.

Contributors PCR, ROL and VJW contributed to the conception, design and conduct of the study. PCR analysed the study data. PCR, ROL and VJW interpreted the study data. PCR wrote the first draft of the manuscript. PCR, ROL and VJW contributed important intellectual content to subsequent drafts of the manuscript. All authors have read and approved the final manuscript.

Funding Sandoz International GmbH provided funding for this study. The funding agreement is available online (http://sites.bu.edu/evaluatingaccessaccessaccelerated/agreements/).

Disclaimer The funder had no role in study design, data collection and analysis, decision to publish or preparation of the manuscript.

Competing interests None declared.

Patient consent Obtained.

Ethics approval The study protocol was approved by the Institutional Review Boards at Strathmore University in Kenya and at Boston University in the USA.

Provenance and peer review Not commissioned; externally peer reviewed.

Data sharing statement Data from this study can be accessed online (sites.bu. edu/evaluatingaccess-novartisaccess/kenya/baseline-database-download/).

Open access This is an open access article distributed in accordance with the Creative Commons Attribution Non Commercial (CC BY-NC 4.0) license, which permits others to distribute, remix, adapt, build upon this work non-commercially, and license their derivative works on different terms, provided the original work is properly cited and the use is non-commercial. See: http://creativecommons.org/ licenses/by-nc/4.0/

(c) Article author(s) (or their employer(s) unless otherwise stated in the text of the article) 2018. All rights reserved. No commercial use is permitted unless otherwise expressly granted.

\section{REFERENCES}

1. Wirtz VJ, Hogerzeil HV, Gray AL, et al. Essential medicines for universal health coverage. Lancet 2017;389:403-76.

2. World Health Organization. Equitable access to essential medicines: a framework for collective action. Geneva: WHO, 2004.

3. Hogerzeil HV, Mirza Z. The world medicines situation 2011: access to essential medicines as part of the right to health. Geneva: WHO, 2011.

4. Gakidou E, Mallinger L, Abbott-Klafter J, et al. Management of diabetes and associated cardiovascular risk factors in seven countries: a comparison of data from national health examination surveys. Bull World Health Organ 2011;89:172-83.

5. Yusuf S, Islam S, Chow CK, et al. Use of secondary prevention drugs for cardiovascular disease in the community in high-income, middle- 
income, and low-income countries (the PURE Study): a prospective epidemiological survey. Lancet 2011;378:1231-43.

6. Gillies TD, Tomlin AM, Dovey SM, et al. Ethnic disparities in asthma treatment and outcomes in children aged under 15 years in New Zealand: analysis of national databases. Prim Care Respir $\mathrm{J}$ 2013;22:312-8.

7. Le C, Jun D, Zhankun S, et al. Socioeconomic differences in diabetes prevalence, awareness, and treatment in rural southwest China. Trop Med Int Health 2011;16:1070-6.

8. Khatib R, McKee M, Shannon H, et al. Availability and affordability of cardiovascular disease medicines and their effect on use in highincome, middle-income, and low-income countries: an analysis of the PURE study data. Lancet 2016;387:61-9.

9. Christiani Y, Dhippayom T, Chaiyakunapruk N. Assessing evidence of inequalities in access to medication for diabetic populations in low- and middle-income countries: a systematic review. Glob Health Action 2016;9:32505.

10. Vialle-Valentin CE, Serumaga B, Wagner AK, et al. Evidence on access to medicines for chronic diseases from household surveys in five low- and middle-income countries. Health Policy Plan 2015;30:1044-52.

11. Attaei MW, Khatib R, McKee M, et al. Availability and affordability of blood pressure-lowering medicines and the effect on blood pressure control in high-income, middle-income, and low-income countries: an analysis of the PURE study data. Lancet Public Health 2017;2:e411-e419.

12. Bigdeli M, Jacobs B, Tomson G, et al. Access to medicines from a health system perspective. Health Policy Plan 2013;28:692-704.

13. Wirtz VJ, Serván-Mori E, Heredia-Pi I, et al. Factors associated with medicine utilization and expenditure in Mexico. Salud Publica Mexico 2013;55:S112-22.

14. Braveman P, Gruskin S. Poverty, equity, human rights and health. Bull World Health Organ 2003;81:539-45.

15. United Nations. Sustainable Development Goals. 2015. https://sust ainabledevelopment.un.org/sdgs (accessed 12 Dec 2017).

16. Rockers PC, Wirtz VJ, Vian T, et al. Study protocol for a clusterrandomised controlled trial of an NCD access to medicines initiative: evaluation of Novartis Access in Kenya. BMJ Open 2016;6:e013386.

17. World Bank. Kenya Country profile. http://data.worldbank.org/ country/kenya (accessed 6 Dec 2017).

18. World Health Organization. Global Health Expenditure Database. http://apps.who.int/nha/database/ (accessed 9 Jan 2018).

19. World Health Organization. UN, Kenyan government take broadbased approach to fighting NCDs. Geneva: WHO, 2014.

20. Ait-Khaled N, Odhiambo J, Pearce N, et al. Prevalence of symptoms of asthma, rhinitis and eczema in 13- to 14-year-old children in
Africa: the International Study of Asthma and Allergies in Childhood Phase III. Allergy 2007:62:247-58.

21. Esamai F, Anabwani GM. Prevalence of asthma, allergic rhinitis and dermatitis in primary school children in Uasin Gishu district, Kenya. East Afr Med J 1996;73:474-8.

22. World Health Organization. Noncommunicable diseases country profiles: Kenya. Geneva: WHO, 2011.

23. Ministry of Medical Services [Kenya], Ministry of Public Health \& Sanitation [Kenya]. Access to essential medicines in Kenya: a health facility survey. 2009. apps.who.int/medicinedocs/en/d/Js18695en/

24. Filmer D, Pritchett LH. Estimating wealth effects without expenditure data-or tears: an application to educational enrollments in states of India. Demography 2001;38:115-32.

25. Kenya National Bureau of Statistics, Ministry of Health/Kenya, National AIDS Control Council/Kenya. Kenya demographic and health survey 2014. Rockville, MD, USA: Kenya National Bureau of Statistics, Ministry of Health/Kenya, National AIDS Control Council/Kenya, Kenya Medical Research Institute, National Council for Population and Development/Kenya, and ICF International, 2015.

26. StataCorp. Stata statistical software: release 14. College Station, TX: StataCorp LP, 2015.

27. Burke WJ, Jayne TS. Spatial disadvantages or spatial poverty traps. household evidence from rural Kenya: Overseas Development Institute, 2010.

28. Porter G. Transport services and their impact on poverty and growth in rural sub-Saharan africa: a review of recent research and future research needs. Transp Rev 2014;34:25-45.

29. Mendoza RU. Why do the poor pay more? Exploring the poverty penalty concept. J Int Dev 2011;23:1-28.

30. Goodman C, Kachur SP, Abdulla S, et al. Concentration and drug prices in the retail market for malaria treatment in rural Tanzania. Health Econ 2009;18:727-42.

31. Gellad WF, Choudhry NK, Friedberg MW, et al. Variation in drug prices at pharmacies: are prices higher in poorer areas? Health Serv Res 2009;44:606-17.

32. Qato DM, Daviglus ML, Wilder J, et al. 'Pharmacy deserts' are prevalent in Chicago's predominantly minority communities, raising medication access concerns. Health Aff 2014;33:1958-65.

33. Pinkerton JR, Hassinger EW, O'Brien DJ. Inshopping by residents of small communities. Rural Sociol 1995;60:467-80.

34. Tetteh E. Providing affordable essential medicines to African households: the missing policies and institutions for price containment. Soc Sci Med 2008;66:569-81.

35. Okech TC, Lelegwe SL. Analysis of universal health coverage and equity on health care in Kenya. Glob J Health Sci 2016;8:218. 